\section{Delivery of nutraceuticals using nanotechnology}

Sir,

The editorial on delivery of nutraceuticals using nanotechnology is very interesting. ${ }^{[1]}$ As noted, successful formulation of new nanosubstance is the hope. However, the effectiveness and safety is still the consideration. ${ }^{[1,2]}$ The concern is further testing of the new nano-product. A good testing system is needed. Generally in vitro experiment might be convenient but it cannot answer the question. There are many concerns of the nano-products. The in vivo stability of the new product must be studied. Indeed, the nanosubstance is usually highly sensitive and aggregation can easily occur. As a result, changes in the physical and biochemical properties can be expected. On the other hand,

\begin{tabular}{|l|l|}
\hline \multicolumn{2}{|c|}{ Access this article online } \\
\hline Quick Response Code: & Website: \\
\hline & www.jpionline.org \\
\cline { 2 - 3 } & DOI: \\
\hline
\end{tabular}

when a biochemical substance is changed to nano-level, there must be changes in its physical and biochemical properties. These considerations are recommended for nano-nutraceutical products: a) confirmation of their nutraceutical properties at nano-level, b) confirmation of good production process, c) confirmation of the quality and stability of the product, d) good product test to confirm efficacy and safety, and e) long-term follow-up to study the unwanted adverse effect of the product.

Viroj Wiwanitkit

Wiwanitkit House, Bangkhae, Bangkok, Thailand, Hainan Medical University, China, Joseph Ayobabalola University, Nigeria, Faculty of Medicine, University of Nis, Serbia

Address for correspondence: Prof. Viroj Wiwanitkit, Wiwanitkit House, Bangkhae, Bangkok, Thailand, Hainan Medical University, China, Joseph Ayobabalola University, Nigeria, Faculty of Medicine, University of Nis, Serbia. E-mail: wviroj@yahoo.com

\section{REFERENCES}

1. Sahni JK. Exploring delivery of nutraceuticals using nanotechnology. Int J Pharm Investig 2012;2:53.

2. Wiwanitkit $\mathrm{V}$. New anti-neoplastic drug test using in vitro model: What to be concern?. Daru J Pharm Sci 2012;20:65.

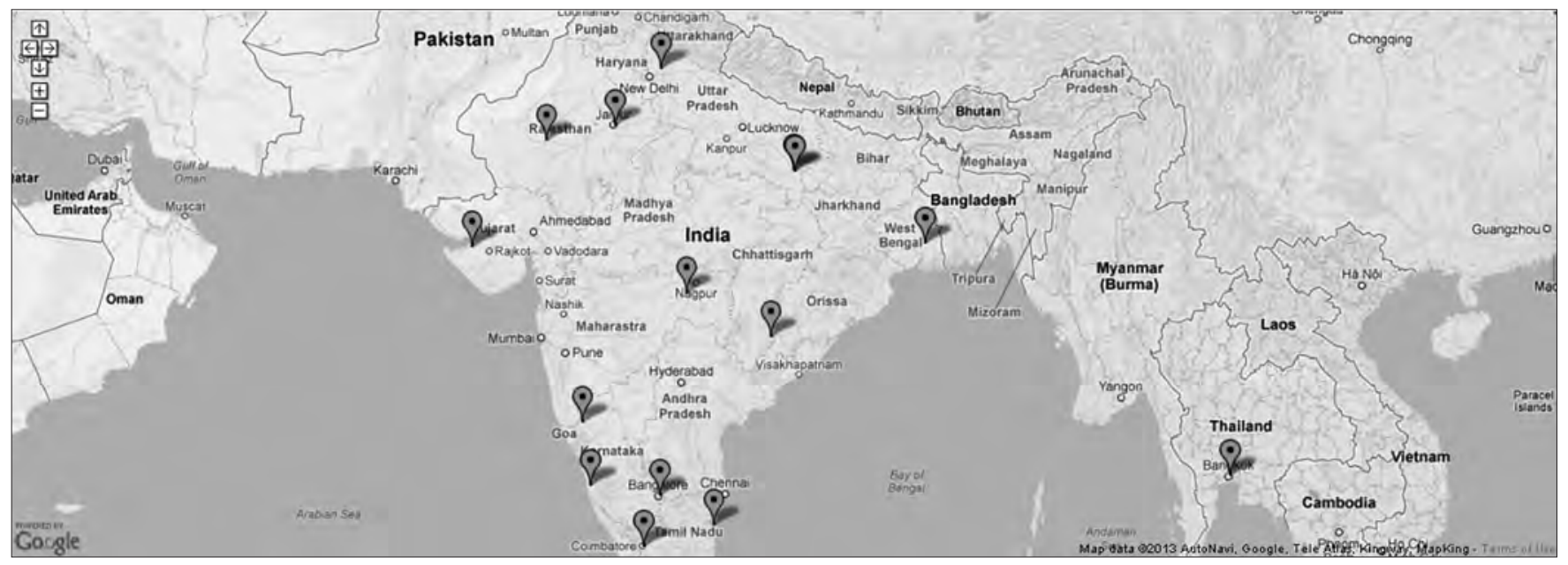

Please note that not all the institutions may get mapped due to non-availability of requisite information in Google Map. For AlM of other issues, please check Archives/Back Issues page on the journal's website. 